\title{
Factors influencing tobacco use treatment patterns among Vietnamese health care providers working in community health centers
}

\author{
Donna Shelley ${ }^{1 *}$, Tuo-Yen Tseng ${ }^{1}$, Hieu Pham¹, Linh Nguyen², Sarah Keithly ${ }^{2}$, Frances Stillman ${ }^{3}$ and Nam Nguyen ${ }^{2}$
}

\begin{abstract}
Background: Almost half of adult men in Viet Nam are current smokers, a smoking prevalence that is the second highest among South East Asian countries (SEAC). Although Viet Nam has a strong public health delivery system, according to the 2010 Global Adult Tobacco Survey, services to treat tobacco dependence are not readily available to smokers. The purpose of this study was to characterize current tobacco use treatment patterns among Vietnamese health care providers and factors influencing adherence to guideline recommended tobacco use screening and cessation interventions.

Methods: A cross sectional survey of 134 health care providers including physicians, nurses, midwives, physician assistants and pharmacists working in 23 community health centers in Viet Nam.

Results: $23 \%$ of providers reported screening patients for tobacco use, $33 \%$ offered advice to quit and less than $10 \%$ offered assistance to half or more of their patients in the past three months. Older age, attitudes, self-efficacy and normative beliefs were associated with screening for tobacco use. Normative beliefs were associated with offering advice to quit. However in the logistic regression analysis only normative beliefs remained significant for both screening and offering advice to quit. Over $90 \%$ of providers reported having never received training related to tobacco use treatment. Major barriers to treating tobacco use included lack of training, lack of referral resources and staff to support counseling, and lack of patient interest.
\end{abstract}

Conclusions: Despite ratifying the FCTC, Viet Nam has not made progress in implementing policies and systems to ensure that smokers are receiving evidence-based treatment. This study suggests a need to change organizational norms through changes in national policies, training and local system-level changes that facilitate treatment.

Keywords: Cessation, Tobacco, Clinical practice guidelines, Adherence guidelines, Viet Nam

\section{Background}

Almost half of adult men in Viet Nam are current smokers, a smoking prevalence that is the second highest among South East Asian countries [1]. Although smoking rates among women are low (1.4\%), exposure to secondhand smoke is significant, ranging from 55.3-67.6\% [1-3]. If current smoking rates are not addressed it is estimated that in 10 years, tobacco use will be responsible for about $25 \%$ of adult male deaths in Viet Nam [4].

\footnotetext{
* Correspondence: donna.shelley@nyumc.org

'Department of Population Health, New York University School of Medicine, 227 East 30th Street, New York, NY 10016, USA

Full list of author information is available at the end of the article
}

Evidence-based, cost effective approaches to treating tobacco use exist and are defined by the U.S. Public Health Service Guideline (PHS Guideline) on Treating Tobacco use and Dependence [5]. The Guideline, which is endorsed by the World Health Organization (WHO), is based on a meta-analysis of over 6000 studies and provides strong evidence that asking all patients about tobacco use, advising smokers to quit, assessing readiness, providing assistance (e.g., counseling) and arranging follow-up (the 5As) can significantly increase smoking abstinence rates [5]. Yet, in the U.S. and globally, adoption of guideline recommended care into routine public health and clinical practice is suboptimal $[6,7]$.

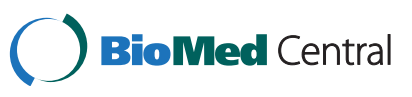

(c) 2014 Shelley et al.; licensee BioMed Central Ltd. This is an open access article distributed under the terms of the Creative Commons Attribution License (http://creativecommons.org/licenses/by/2.0), which permits unrestricted use, distribution, and reproduction in any medium, provided the original work is properly cited. 
Implementing evidence-based tobacco use treatment is a core provision in the WHO Framework Convention on Tobacco Control (FCTC). The FCTC is an evidence-based treaty that was developed by the $\mathrm{WHO}$ in response to the globalization of the tobacco epidemic [8]. Article 14 of the WHO FCTC states "each country shall take effective measures to promote cessation and adequate treatment for tobacco dependence" [9]. In an effort to comply with Article 14, over 20 countries have developed guidelines for treating tobacco use [10]. Although Viet Nam has a strong public health delivery system, according to the 2010 Global Adult Tobacco Survey (GATS), services to treat tobacco dependence are not readily available to smokers [1]. The dearth of effective tobacco cessation services in Viet Nam is not the result of a lack of commitment to tobacco control. The government ratified the FCTC in 2004, and has enacted an ambitious National Tobacco Control Action Plan (Decision No. 1315/QD-TTg) for the Implementation of the FCTC.

Despite the high rates of tobacco use in Viet Nam we are not aware of any studies that have assessed smoking cessation practice patterns among Vietnamese health care providers. Moreover, we are not aware of any studies that have assessed perceived barriers to adhering to clinical practice guidelines or normative beliefs in relation to treating tobacco use among health care professionals in South East Asian Countries (SEACs). These factors have been shown to influence provider adherence to guideline recommended care across a range of preventive services [11-15]. Therefore, understanding the association between these potentially modifiable factors and tobacco use treatment practice patterns may help guide policy and system changes to address gaps in implementing comprehensive smoking cessation interventions throughout the public health system in Viet Nam and other SEACs.

Within this context, the aim of this paper is to characterize current cessation intervention practices and examine behavioral and organizational factors that may influence adherence to recommended guidelines for treating tobacco use among health care providers working in commune health centers in Hanoi, Vietnam [14,16].

\section{Methods}

\section{Study overview}

The study was conducted as part of a formative evaluation prior to implementing a randomized controlled trial study to assess strategies for implementing tobacco use treatment guidelines in the public health system in Viet Nam. The study was conducted in Dong Anh district - a suburban district in Hanoi, the capital city of Viet Nam. With approval from the director of District Health Center, 23 commune health centers were invited to participate. Subsequent staff meetings were held at each site to describe the study in more detail. Follow-up appointments were made with staff who agreed to participate. Participants received $\$ 4(80,000 \mathrm{VND})$ each as compensation for their time. The institutional review boards of the Institute of Social Medical Studies (ISMS) and the New York University School of Medicine approved this research.

\section{Study sites}

The Vietnamese health care system is hierarchically organized into four administrative levels: central, province, district and commune. At the central level is the Ministry of Health $(\mathrm{MOH})$, the main national authority in the health sector which formulates and implements national health policies and programs. The provincial-level health system consists of Provincial Health Departments and Preventive Health Centers, which are administered by the Provincial People's Committee in each province. At the district level, the District People's Committee administers district health centers and district-level hospitals. Within districts the commune health centers ( $\mathrm{CHCs})$ serve as the primary access point for public health and preventive care services in Viet Nam, each providing services for an average of 50007000 people in their surrounding community.

$\mathrm{CHCs}$ are charged with implementing 10 national health programs, diagnosis and treatment of common diseases, provision of health counseling and education, referral services, pre- and post-natal care, family planning, and food hygiene and safety. Each $\mathrm{CHC}$ is staffed by $5-6$ health care providers, including one physician and three to five other health professionals (Physician assistants, nurses, midwives and/or pharmacists). In addition, each $\mathrm{CHC}$ is supported by a network of $8-10$ village health workers (similar in roles and responsibilities to community health workers) who primarily conduct outreach work in the villages within a commune.

\section{Study design and measures}

In November 2012 a cross sectional survey was conducted with 134 health care providers including physicians, nurses, physician assistants, pharmacists and midwives practicing in $23 \mathrm{CHCs}$. After obtaining verbal consent, a trained research assistant from ISMS administered the surveys in person. The survey measured demographic data (e.g., gender, age), smoking status and current practice patterns related to tobacco use treatment. Current smoking was defined as having smoked at least 100 cigarettes in their lifetime and having smoked some days or everyday. Former smokers were defined as those who smoked $>100$ cigarettes during their lifetime but answered not at all in response to the question, do you now smoke every day, some days, or not at all? Provider adherence to guideline recommended tobacco use treatment was assessed using a validated tool that assessed four of the 5As with the following questions: In the past three months 1) How many new patients did you ask about their tobacco use status? 
2) Among all of your patients, how many did you ask about their tobacco use status? 3) For how many patients who are tobacco users did you assess readiness to quit? 4) How many patients who are tobacco users did you give advice or counsel to quit, 5) How many patients who are tobacco users did you refer to a community stop smoking program or counselor for help quitting, and 6) How many patients who are tobacco users did you prescribe smoking cessation medication like the nicotine patch [17]. Using a 5-point likert scale answers included none, few, half, more than half or all or most.

They survey also examined factors that may influence provider adherence to tobacco use treatment guidelines. These questions were informed by the Theory of Planned Behavior (TPB) which posits that individual cognitions including attitudes towards a behavior and social norms related to performing a behavior guide individual actions [15]. In addition to being one of the most widely tested theories for predicting individual behavior change, TPB has been shown to be able to predict clinician behavior [11-15]. Questions measuring TPB constructs were adapted from Francis and colleagues and the WHO Global Health Professional Survey $[11,18]$.

All of the questions used a 4-point likert scale (strongly disagree, disagree, agree, strongly agree). Attitudes were measured with four questions: 1) most smokers do not want to quit, 2) advice from a doctor or nurse in one of the best ways to help people stop smoking, 3) smoking cessation counseling is not a priority to me, and 4) patients appreciate it when I provide smoking cessation counseling. Normative beliefs were measured with two questions: 1) my supervisors think that helping smokers quit is a priority, and 2) most of the staff thinks that promoting smoking cessation is part of their job. Self-efficacy was measured with three questions: 1) I am confident in my ability to help patients stop smoking, 2) I have the training I need to help smokers quit smoking, and 3) I am not aware of the best treatments for helping patients stop smoking. Barriers were assessed using a 4-point likert scale ranging from not a barrier to major barrier. Questions about barriers were based on previous literature from studies in China and the US $[16,19]$. The surveys were translated from the English version to the Vietnamese version and then back-translated to English before conducting a pilot test with 10 participants to assess comprehension and relevance.

\section{Data analysis}

A data entry specialist entered the survey information into the database in EpiInfo V.6.04. To ensure accuracy, $10 \%$ random samples of the data were cross validated by the data entry specialist and research assistants. Data were analyzed by using IBM SPSS Statistics for Windows version 20.0 (Armonk, NY: IBM Corp.). Descriptive statistics were used to summarize the provider and site characteristics, responses to questions about barriers to treatment, attitudes, norms and self-efficacy as well as rates of asking, advising, assessing readiness to quit and offering cessation assistance. Scores on individual items were averaged within each TPB-related construct to produce a composite measure for analysis. We reversed negative questions about attitudes and self-efficacy so that a high summary score always indicated stronger or more positive beliefs.

We used Chi square analysis, T-test and logistic regression to assess the relationships between variables. Smoking status and gender were highly correlated; therefore we included only gender in the analyses. Significance was established as $\mathrm{p} \leq 0.05$ (2-tailed).

\section{Results}

Ninety five percent of providers working in the $23 \mathrm{CHCs}$ completed the survey. Table 1 shows characteristics of the participating health professionals and the $\mathrm{CHCs}$ in which they work. Consistent with national data in Viet Nam, $80 \%$ of the health care providers were female $(10 \%$ physician, 73\% nurse or Physician Assistant) [20]. Less than $10 \%$ were current smokers and these were all male clinicians. Ninety four percent had not participated in formal training on tobacco use treatment. Among the $74 \%$ who reported a smoking policy in their $\mathrm{CHC}$, only $26.5 \%$ reported a total ban.

\section{Table 1 Provider and practice characteristics}

\begin{tabular}{lcc}
\hline Characteristic & N & \%/Mean (SD) \\
\hline Gender & 27 & $20.1 \%$ \\
Male & 107 & $79.9 \%$ \\
$\quad$ Female & & $37.4(10.0)$ \\
Age (mean years) & & \\
$\quad$ Profession & 14 & $10.4 \%$ \\
Physician & 50 & $37.3 \%$ \\
$\quad$ Nurse & 18 & $13.4 \%$ \\
Midwife & 49 & $36.6 \%$ \\
Physician's assistant & 3 & $2.2 \%$ \\
Pharmacist & & \\
Smoking status & 13 & $9.7 \%$ \\
Current & 109 & $81.3 \%$ \\
Never & 12 & $8.9 \%$ \\
Former & 126 & $94 \%$ \\
Have NOT participated in tobacco & & \\
use treatment training & & $12.7 \%$ \\
Smoking policy in the CHC & 17 & \\
No & 98 & \\
Yes & 19 & \\
Don't know & & \\
\hline
\end{tabular}


Over $90 \%$ agreed or strongly agreed that advice from a provider is one of the best ways to help people stop smoking, but almost half reported that offering smoking cessation counseling is not a priority for them (Table 2). Self reported levels of confidence were in conflict with reports of training and awareness of best treatment. Over $85 \%$ reported that they were confident in their ability to help smokers, but $60 \%$ agreed or strongly agreed that they were not aware of the best treatment to help patients stop smoking and only $29 \%$ agreed or strongly agreed that they had the training needed to help smokers quit. Over $80 \%$ agreed or strongly agreed that offering smoking cessation treatment was part of their job and that their supervisor thinks that helping smokers is a priority. Table 2 also shows the percent of providers who reported adherence to guidelines for screening and treating tobacco use. Twenty three percent of providers reported screening half or more of their patients, $33 \%$ provided advice to smokers, and less than $10 \%$ offered assistance (i.e., counseling, referral or medication) to half or more of their patients.

The most commonly reported barriers to treatment (Figure 1) were lack of training (70\%) lack of referral resource in the community or additional staff to assist with cessation counseling (69\%) and lack of patient interest (80\%). Table 3 shows the results of the bivariate analysis examining the correlation between provider practice patterns and provider characteristics, smoke free policies and TPB constructs. Older age, self-efficacy, attitudes and norms that endorsed tobacco use treatment were associated with providers routinely screening half or more of their patients. Routinely offering advice to quit was associated with normative beliefs.

In the multiple logistic regression analyses (Table 4) normative beliefs was the only factor that remained significantly associated with asking about tobacco use (OR 3.47, $\mathrm{p}<.014)$ and advising patients to quit (OR 5.15, $\mathrm{p}<.005)$.

\section{Discussion}

Vietnamese providers working in $\mathrm{CHCs}$ in Hanoi reported low rates of tobacco use screening (23\%). Although once smokers were identified providers were more likely to advice smokers to quit (33\%), less than $10 \%$ provided more in-depth cessation assistance (i.e., brief counseling, referral or prescription). Similarly, a survey among 447 physicians in Indonesia found low rates of adherence to recommended screening and cessation treatment practices (e.g., $28 \%$ routinely asked about patients' smoking status) [21]. In contrast, surveys of hospital-based physicians in China have found higher rates tobacco use screening and advise to quit. In a study in five hospitals in China $71 \%$ of physicians reported asking about smoking and $78 \%$ offering advice to quit [22]. A 2004 survey of 3552 hospital-based

Table 2 Attitudes, self-efficacy, norms and practice patterns related to treating tobacco use

\begin{tabular}{|c|c|c|}
\hline Constructs & N (\%) Agree/Strongly agree & Mean (SD) \\
\hline \multicolumn{3}{|l|}{ Attitudes $^{\mathrm{a}}$} \\
\hline Offering smoking cessation treatment to my patients is part of my job. & $116(86.6)$ & $3.30(.78)$ \\
\hline Most smokers don't want to quit. & $94(70.1)$ & $2.98(.99)$ \\
\hline Smoking cessation counseling is not a priority to me. & $71(53.0)$ & $2.40(.96)$ \\
\hline Advice from a doctor or nurse is one of the best ways to help people stop smoking. & $129(96.3)$ & $3.75(.54)$ \\
\hline Patients appreciate it when I provide smoking cessation counseling. & $111(82.8)$ & $3.2(.77)$ \\
\hline \multicolumn{3}{|l|}{ Self-efficacy ${ }^{\mathbf{b}}$} \\
\hline I am confident in my ability to help patients stop smoking. & $117(87.3)$ & $3.22(.78)$ \\
\hline I have the training I need to help smokers quit. & $39(29.1)$ & $1.93(1.06)$ \\
\hline I am not aware of the best treatments for helping patients stop smoking. & $80(60.2)$ & $2.64(1.03)$ \\
\hline \multicolumn{3}{|l|}{ Norms $s^{c}$} \\
\hline Most of the staff think that promoting smoking cessation is part of their job & $120(89.6)$ & $3.40(.73)$ \\
\hline My supervisors think that helping smokers quit is a priority. & $112(83.6)$ & $3.23(.76)$ \\
\hline Practice patterns (in past 3 months)* & Half or more patients & \\
\hline Ask about tobacco use & $31(23.1)$ & \\
\hline Advise to quit & $32(33.0)$ & \\
\hline Assess readiness to quit & $14(14.4)$ & \\
\hline Assist** & $8(8.3)$ & \\
\hline
\end{tabular}

${ }^{\mathrm{a} C r o n b a c h ' s ~ a l p h a ~}=0.32,{ }^{\mathrm{b}} \mathrm{Cronbach}$ 's alpha $=0.27,{ }^{\mathrm{C}}$ Cronbach's alpha $=0.42$.

*4 point likert scale included: none, few, half, more than half or all or most.

${ }^{* *}$ Assisted is defined as referring patients for counseling and/or prescribing cessation pharmacotherapy. 


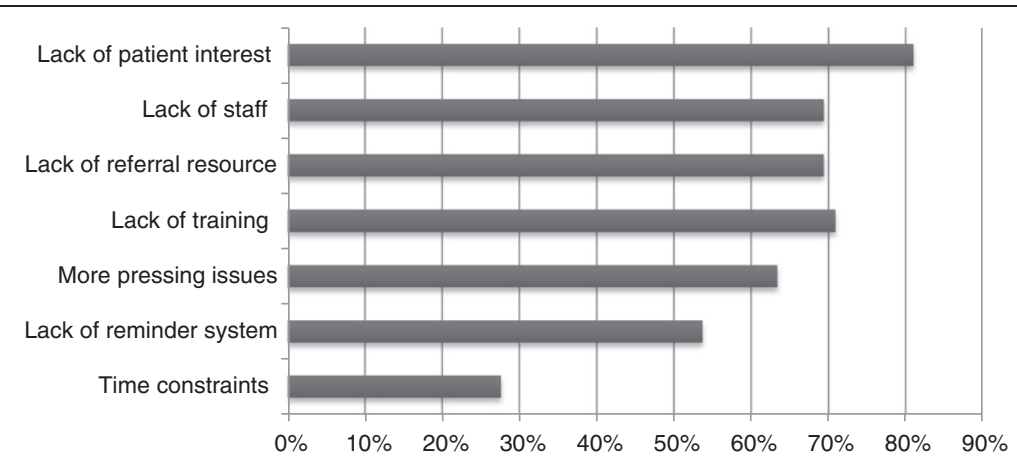

Figure 1 Barriers to adhering to tobacco use treatment guidelines (moderate and/or major).

physicians from six Chinese cities found that $48 \%$ screened for tobacco use and $64 \%$ reported advising smokers to quit however, only $7 \%$ offered pharmacotherapy [23].

Lower rates of adherence to guideline recommendations in this study may be due to the focus on communitybased clinicians and inclusion of non-physician health care professionals. Over $90 \%$ of providers in this study reported no previous training related to tobacco use treatment and less than a third reported they had the training needed to help smokers quit. Ng and colleagues found that community physicians in Indonesia were less likely to screen for tobacco use or offer advice to quit compared with medical school faculty and residents. They were also less likely to feel that they had sufficient training or experience to help smokers quit [21]. Not having an affiliation with an academic institution or major hospital may diminish opportunities for training on tobacco use treatment among clinicians in $\mathrm{CHCs}$, particularly if this is not considered a national prevention priority for $\mathrm{CHCs}$ to manage, as is the case in Viet Nam.

We are aware of only two other studies that have included community-based health care professionals in assessments of tobacco use treatment [21,23]. Yet, $\mathrm{CHCs}$ are the front line for preventive service delivery in Viet Nam and other low-middle income countries (LMICs). A program that offers training of physicians and allied health professionals working in CHCs is urgently needed. Global Bridges, a not for profit organization, is providing evidence-based training in treatment and advocacy and is working towards implementing Article 14 in four regions but has not yet expanded this program to include SEACs [24]. Additional funding should be directed toward building capacity among provider organizations and Ministries of Health to disseminate tobacco use treatment-related education and training programs throughout public health care delivery systems in these countries.

Table 3 Correlates of tobacco use screening and advise to quit delivered by health care providers

\begin{tabular}{|c|c|c|c|c|c|c|}
\hline \multirow[b]{2}{*}{ Constructs } & \multirow[b]{2}{*}{ None or few patients } & \multicolumn{2}{|c|}{ Asked } & \multicolumn{3}{|c|}{ Advised to quit } \\
\hline & & Half or more & p-value & None or few patients & Half or more & p-value \\
\hline Age & $36.2(9.71)$ & $41.48(10.17)$ & .01 & $36.4(10.06)$ & $39.66(9.90)$ & .13 \\
\hline Gender & & & .20 & & & .09 \\
\hline Female & $85(79.4 \%)$ & $22(20.6 \%)$ & & $52(72.2 \%)$ & $20(27.8 \%)$ & \\
\hline Male & $18(66.7 \%)$ & $9(33.3 \%)$ & & $13(52.0 \%)$ & $12(48.0 \%)$ & \\
\hline Smoking status & & & 1.0 & & & .52 \\
\hline Current smoker & $10(76.9 \%)$ & $3(23.1 \%)$ & & 7 (58.3\%) & $5(41.7 \%)$ & \\
\hline Former or nonsmoker & $93(76.9 \%)$ & $28(23.1 \%)$ & & $58(68.2 \%)$ & $27(31.8 \%)$ & \\
\hline Clinic smoking policy & & & 1.0 & & & 1.0 \\
\hline Yes & $74(75.5 \%)$ & $24(24.5 \%)$ & & $49(66.2 \%)$ & $25(33.8 \%)$ & \\
\hline No & $13(76.5 \%)$ & $4(23.5 \%)$ & & $10(71.4 \%)$ & $4(28.6 \%)$ & \\
\hline Mean score attitudes & $2.9(0.43)$ & $3.1(0.39)$ & .01 & $3.0(0.40)$ & $3.1(0.40)$ & .41 \\
\hline Mean score self-efficacy & $2.4(0.64)$ & $2.7(0.53)$ & .02 & $2.5(0.60)$ & $2.6(0.45)$ & .27 \\
\hline Mean score norms & $3.2(0.61)$ & $3.6(0.42)$ & $<.001$ & $3.3(0.52)$ & $3.6(0.54)$ & .001 \\
\hline
\end{tabular}

Means with SD in parenthesis are show for continuous variables; counts with percentages are shown for categorical variables. T-test was used for continuous variables and Chi square test for categorical variables. 
Table 4 Multiple logistic regression

\begin{tabular}{lccccc}
\hline Independent variables & \multicolumn{2}{c}{ Asked $(\mathbf{n}=\mathbf{1 1 5})$ none or few vs. half or more } & & \multicolumn{2}{c}{ Advised to quit $(\mathbf{n}=\mathbf{8 8})$ none or few vs. half or more } \\
\cline { 2 - 3 } \cline { 5 - 6 } & OR $(\mathbf{9 5} \% \mathbf{C l})$ & $\mathbf{p}$-value & & OR (95\% Cl) & p-value \\
\hline Age & $1.06(1.01-1.12)$ & .020 & $.05(0.99-1.11)$ & 0.10 \\
Female & $1.04(0.34-3.16)$ & .952 & $0.51(0.16-1.61)$ & 0.25 \\
Smoking policy & $0.91(0.23-3.59)$ & .894 & & $1.15(0.29-4.65)$ & 0.843 \\
Attitudes & $1.75(0.45-6.83)$ & .418 & $0.59(0.15-2.41)$ & 0.463 \\
Self-efficacy & $1.39(0.57-3.37)$ & .471 & $0.81(0.29-2.26)$ & 0.69 \\
Norms & $3.47(1.28-9.38)$ & .014 & $5.15(1.65-16.1)$ & 0.005 \\
\hline
\end{tabular}

Vietnamese health care provider's attitudes towards delivering cessation interventions were generally positive. Similar to previous surveys of providers practicing in China and other SEACs, the discrepancy between attitudes and practice may be largely related to a lack of knowledge about treatment strategies. Several studies have found a significant association between lack of training and low cessation intervention activities among physicians [21-23,25]. Although our smaller sample size and the lack of heterogeneity in this response (94\% reported no training) may have precluded our ability to demonstrate this association, a lack of training was one of the top two barriers, cited by providers, to adhering to tobacco use treatment guidelines.

Another finding that may be related to a lack of training was the large percentage of providers that agreed with the statement that smokers don't want to quit (70\%). A lack of patient interest in quitting was also the most frequently cited barrier to asking about tobacco use and offering cessation assistance. This belief is not supported by national data and may have contributed to the low rates of tobacco use screening. According to the 2010 Global Adult Tobacco Survey, two-thirds of current smokers in Vietnam are planning to or thinking about quitting and over half attempt to quit annually [26]. Other reported barriers suggest that gaps in staffing and systems to facilitate routine screening and treatment, are also contributing to low levels of cessation interventions. A study of hospital-based physicians in China found that organizational support was associated with a greater level of physician delivered advice to quit [26]. Although not well studied in LMICs, there is a large literature supporting the need for organizational and system level changes to enhance adoption of the full spectrum (5As) of evidence based tobacco use treatment $[5,6,27]$.

Similar research is needed to test strategies for implementing and dissemination guidelines in these critically important preventive health care delivery settings. Novel models of care that address the lack of staff and referral resources could include leveraging the robust community health worker infrastructure in many LMICs, including Viet Nam, to serve as a referral resource in the same way that smoker telephone quitlines offer providers in several countries an evidence-based counseling option for their patients [6,28-31].

Further examination of variables specified by the TPB showed that only normative beliefs, which have not been evaluated in previous surveys of providers in LMICs, were strongly associated with tobacco use screening and cessation advice. A study in China did find that providers with positive attitudes towards treatment were significantly more likely to ask about tobacco use but similarly found no association with cessation advice [26]. This is in contrast to two recent systematic reviews suggest that TPB can be been applied to explain clinician behavior $[12,13]$. However, the studies included in these reviews were conducted in high income countries and none of the interventions being tested included adhering to tobacco use treatment guidelines as the target behavior.

Our finding of a strong association between norms and tobacco use screening and advice to quit may be related to Viet Nam's cultural emphasis on collectivism and CHC's focus on implementing only those practices that are consistent with national and provincial priorities. This finding, albeit drawn from one district in Hanoi, emphasizes the need to work with and obtain support from organizational authorities (i.e., Ministry of Health and District Health leaders) for implementing and disseminating tobacco use treatment guidelines into routine preventive services in $\mathrm{CHCs}$. A recent analysis of experience building capacity for implementation of the FCTC for tobacco control in Viet Nam found that organizational infrastructure, leadership and expertise, partnership and networks and data and evidence from research were key components in efforts to meet FCTC commitments, including the goals of Article 14 [32].

Clearly a wide range of factors can influence clinical practice including individual beliefs as well as political and organizational context $[16,33]$. However, our understanding of these factors is incomplete, particularly in LMICs. Future research should incorporate both individual and organizational level theories to better inform the design of interventions to increase guideline-concordant tobacco use treatment. 
Similar to previous surveys of health care providers in SEACs we found that smoking rates among health care providers were significantly lower than national average $[1,18]$. In this, and the only other survey of Vietnamese providers, the low smoking rates are explained by low rates of smoking among women who are disproportionally represented in the health care profession in Viet Nam [18]. Health care providers who do not smoke are more likely to express positive attitudes towards their role in offering cessation assistance to smokers, act as role models and influence social values, and are more likely to offer cessation services compared with providers who smoke $[17,18]$. Therefore, the consistent finding that prevalence is low among health care providers practicing in $\mathrm{CHCs}$ in Viet Nam offers additional incentive to focus efforts on training and system changes in these settings.

Limitations of the study include the small sample size and surveying providers in a suburban setting only. Clinicians working in more rural areas may have different perspectives and practice patterns. We also did not include community health workers in the survey. We are not aware of other tobacco-related provider surveys that have included this workforce. However, there is tremendous untapped potential for CHWs to contribute to a team approach to enhancing screening and treatment for tobacco use.

\section{Conclusion}

$\mathrm{CHC}$ 's focus on preventive care, their role as the first access point for the health care system and the availability of services at no cost to a large majority of the population makes them the ideal setting for implementing routine tobacco use screening and treatment. However, closing the gap between evidence for tobacco use treatment and current practices in $\mathrm{CHCs}$ in Viet Nam will require changes in national preventive health services priorities to specifically include Article 14 goals and policies that support implementation of these goals. These include requirements for evidence-based training of all health care professionals, including community health workers, redefining the role of the care team members to identify those responsible for screening and treatment and creating referral options that support provider cessation interventions. Having ratified the FCTC, created an office in the $\mathrm{MOH}$ for tobacco control and passed into law a plan to implement a comprehensive tobacco control program Viet Nam is poised to develop replicable models of care delivery that address gaps in the reach and sustainability of evidence-based tobacco use treatment that could lead to significant reductions in tobacco related morbidity and mortality.

\section{Competing interests}

The authors declare that they have no competing interests.

\section{Authors' contributions}

DS and NN conceived the study, developed the study protocol and the survey tool and wrote the manuscript. SK assisted with survey development and oversight of the study locally in Viet Nam. LN conducted the data collection and data entry. TT and HP conducted data analysis and edited the manuscript and FS assisted with survey design and review of the final manuscript. All authors read and approved the final manuscript.

\section{Author details}

${ }^{1}$ Department of Population Health, New York University School of Medicine, 227 East 30th Street, New York, NY 10016, USA. ${ }^{2}$ Institute of Social Medical Studies, Hanoi, Viet Nam. ${ }^{3}$ Bloomberg School of Public Health, Johns Hopkins University, Baltimore, MD, USA.

Received: 3 July 2013 Accepted: 13 December 2013 Published: 22 January 2014

\section{References}

1. Global Adult Tobacco Survey (GATS) VietNam 2010; http://www.who.int/ tobacco/surveillance/en_tfi_gats_vietNam_report.pdf.

2. Jenkins CN, Dai PX, Ngoc DH, et al: Tobacco use in Vietnam. Prevalence, predictors, and the role of the transnational tobacco corporations. JAMA 1997, 277:1726-1731.

3. Minh HV, Ng N, Wall H, et al: Smoking epidemics and socio-economic predictors of regular use and cessation: Findings from WHO STEPS risk factor surveys in Viet Nam and Indonesia. The Internet J of Epidemiol 2006, 3. doi:10.5580/298c.

4. WHO Western Pacific Region: Viet Nam Health profile. http://www.wpro.who. int/countries/vnm/36VTNpro2011_finaldraft.pdf.

5. Fiore MC, Jaén CR, Baker TB, et al: Treating Tobacco Use and Dependence:2008 Update.Clinical Practice Guideline. Rockville, MD: U.S. Department of Health and Human Services. Public Health Service; 2008.

6. Fiore MC, Keller PA, Curry SJ: Health system changes to facilitate the delivery of tobacco-dependence treatment. Am J Prev Med 2007, 33(6 Suppl):S349-S356.

7. WHO: Tools for Advancing Tobacco Control in the XXIst century; 2003. http:// www.who.int/tobacco/resources/publications/tobacco_dependence/en/.

8. World Health Organization: WHO Framework on Tobacco Control. 2003: http://whqlibdoc.who.int/publications/2003/9241591013.pdf.

9. World Health Organization Conference of the Parties: Guidelines for implementation of Article 14 of the WHO Framework Convention on Tobacco Control. 2010. http://www.who.int/fctc/Guidelines.pdf.

10. National Treatment Guidelines: Treattobacco. http://www.treatobacco.net/ en/page_224.php.

11. Francis JJ, Eccles MP, Johnston M, Whitty P, Grimshaw JM, Kaner EF, Smith L, Walker A: Explaining the effects of an intervention designed to promote evidence-based diabetes care: a theory-based process evaluation of a pragmatic cluster randomised controlled trial. Implement Sci 2008, 3:50. doi:10.1186/1748-5908-3-50.

12. Godin G, Belanger-Gravel A, Eccles M, Grimshaw J: Healthcare professionals' intentions and behaviours: a systematic review of studies based on social cognitive theories. Implement Sci 2008, 3:36. doi:10.1186/17485908-3-36.

13. Eccles MP, Hrisos S, Francis J, Kaner EF, Dickinson HO, Beyer F, Johnston M: Do self-reported intentions predict clinicians' behaviour: a systematic review. Implement Sci 2006, 1:28.

14. Ajzen I: The theory of planned behavior. Organ Behav Hum Dec 1991 50:179-211.

15. Hrisos S, Eccles MP, Francis JJ, Bosch M, Dijkstra R, Johnston M, Grol R, Kaner $E F$, Steen IN: Using psychological theory to understand the clinical management of type 2 diabetes in Primary Care: a comparison across two European countries. BMC Health Serv Res 2009, 9:140. doi:10.1186/ 1472-6963-9-140.

16. Grol R, Wensing M: What drives change? Barriers to and incentives for achieving evidence-based practice. Med J Aust 2004, 180:S57-S60.

17. Hung D, Shelley D: Multilevel analysis of the chronic care model and $5 A$ services for treating tobacco use in urban primary care clinics. Health Serv Res 2009, 44:103-127.

18. Centers for Disease Control and Prevention: Tobacco use and cessation counseling -- Global Health Professionals survey pilot study, 10 countries. MMWR 2005 2005, 54(20):505-509. 
19. Grimshaw J, McAuley $L M$, Bero $L A$, et al: Systematic reviews of the effectiveness of quality improvement strategies and programmes. Qual Saf Health Care 2003, 12:298-303.

20. Lam TH, Jiang C, Chan YF, Chan SS: Smoking cessation intervention practices in Chinese physicians: do gender and smoking status matter? Health Soc Care Community 2011, 19:126-137.

21. Ng N, Prabandari YS, Padmawati RS, Okah F, Haddock CK, Nichter M, Nichter M, Muramoto M, Poston WS, Pyle SA, Mahardinata N, Lando HA: Physician assessment of patient smoking in Indonesia: a public health priority. Tob Control 2007, 16:190-196.

22. Zhou J, Abdullah AS, Pun VC, Huang D, Lu S, Luo S: Smoking status and cessation counseling practices among physicians, Guangxi, China, 2007. Prev Chronic Dis 2010, 7(1):A15.

23. Jiang $Y$, Ong MK, Tong EK, Yang $Y$, Nan $Y$, Gan Q, Hu TW: Chinese physicians and their smoking knowledge, attitudes, and practices. Am J Prev Med 2007, 33:15-22

24. Global Bridges. http://www.globalbridges.org

25. Yan J, Xiao S, Ouyang D, Jiang D, He C, Yi S: Smoking behavior, knowledge, attitudes and practice among health care providers in Changsha city, China. Nicotine Tob Res 2008, 10:737-744.

26. CDC Vietnam Ministry of Health, Hanoi Medical University, WHO: Global Adult Tobacco Survey (GATS) Vietnam 2010. Hanoi: WHO; 2010.

27. Curry $\mathrm{SJ}$ : Organizational interventions to encourage guideline implementation. Chest 2000, 118(2 Suppl):S40-S46.

28. Shelley D, Cantrell J: The effect of linking community health centers to a state-level smoker's quitline on rates of cessation assistance. BMC Health Serv Res 2010, 10:25. doi:10.1186/1472-6963-10-25.

29. Sheffer MA, Baker TB, Fraser D, Adsit RT, McAfee TA, Fiore MC: Fax referrals, academic detailing and tobacco quitline use: a randomized trial. Am J Prev Med 2012, 42(1):21-28.

30. North American Quitline Consortium. http//www.naquitline.org.

31. Chen WL, Xiao D, Henderson S, Zhao L, Jing H, Wang C: Characteristics of callers accessing the tobacco cessation quitline in mainland China. Biomed Environ Sci 2013, 26(8):697-701.

32. Stillman FA, David AM, Kibria N, Phan HT: Building capacity for implementation of the framework convention for tobacco control in Viet Nam: lessons for developing countries. Health Promot Int 2013. Epub ahead of print.

33. Damschroder LJ, Aron DC, Keith RE, Kirsh SR, Alexander JA, Lowery JC: Fostering implementation of health services research findings into practice: a consolidated framework for advancing implementation science. Implement Sci 2009, 7(4):50. doi:10.1186/1748-5908-4-50.

doi:10.1186/1471-2458-14-68

Cite this article as: Shelley et al.: Factors influencing tobacco use treatment patterns among Vietnamese health care providers working in community health centers. BMC Public Health 2014 14:68.

\section{Submit your next manuscript to BioMed Central and take full advantage of:}

- Convenient online submission

- Thorough peer review

- No space constraints or color figure charges

- Immediate publication on acceptance

- Inclusion in PubMed, CAS, Scopus and Google Scholar

- Research which is freely available for redistribution

Submit your manuscript at www.biomedcentral.com/submit 